\title{
Transcranial Low-Level Laser Therapy May Improve Alertness and Awareness in Traumatic Brain Injured Subjects with Severe Disorders of Consciousness: a Case Series
}

\section{Abstract}

Background: Transcranial low-level laser therapy (T-LLT) proved promising in acute stroke studies and in single traumatic brain injured subjects (TBI). It was assumed to increase cortical mitochondrial energy production and/or vasodilatation.

Objective: Within this case series the potential of transcranial lowlevel laser therapy in improving the alertness and awareness in TBI subjects with severe disorders of consciousness will be investigated.

Methods: Following a 21-day baseline, the forehead of five patients, four chronic in a state of unresponsive wakefulness or minimal consciousness, one subacute in the state of akinetic mutism, was stimulated with the T-LLT $\left(785 \mathrm{~nm}, 10 \mathrm{~mW} / \mathrm{cm}^{2}\right.$, CW mode, 21 emitting diodes) for 10 min every workday for six weeks. Follow-up was four weeks after end of intervention. Primary variable was the revised version of the Coma Recovery Scale ( $r$-CRS, $0-23$ ), blindly assessed by an external reviewer with the help of videos.

Results: The r-CRS, almost stable during baseline, improved in all patients during the intervention, from 3 to 12,9 to 12,8 to 12 and 5-12 in the chronic, and from 6 to 21 in the subacute patient. Follow-up revealed a sustained effect. The patient in the state of akinetic mutism improved her competence in the activities of daily living and mobility status. Single epileptic fits occurred in two patients during the intervention.

Conclusion: T-LLT improved the patients' alertness and awareness; epileptic fits were potential side effects. Sham-controlled studies including the quantitative assessment of awareness should follow the case series.
Stefan Hesse ${ }^{1}$, Cordula Werner ${ }^{1}$, Manuela Byhahn²

1 Medical Park Berlin, Neurological Rehabilitation, Charité - University Medicine Berlin.

2 Haus Havelblick, Wachkomastation, Havelschanze 3, 13587 Berlin, Germany.

Contact information:

Stefan Hesse.

Address: Medical Park Berlin, Neurology, An der Mühle 2-9, 13507 Berlin, Germany. Tel: +49-(0)30-300 2409312

Fax: +49-(0)30-300 2409319

”s.hesse@medicalpark.de

Keywords

Brain stimulation, traumatic brain injury, minimal conscious state, near-infrared light, transcranial low-level laser therapy, revised coma recovery scale. 


\section{Introduction}

Patients with severe disorders of consciousness (DOC) are a major challenge to the health care systems worldwide. The reported prevalence was 2-10 per 100.000 inhabitants, the major etiologies are traumatic and anoxic brain lesions. [1]

DOCs can be clinically visualized on a functional continuum encompassing the level of vigilance and awareness. The MultiSociety Task Force on PVS (persistent vegetative state) introduced the terms of unresponsive wakefulness syndrome (UWS) and minimally conscious state (MCS). [2] UWS patients show arousal signs objectified by sustained eye opening and the presence of reflex behavior only. The MCS patients show first signs of awareness recovery, for instance by the visual pursuit of moving stimuli in the front of the patients' eyes or following simple verbal commands. [3] Akinetic mutism is regarded as another clinical entity.

Among the known therapeutic options to promote alertness and awareness in DOCs patients, e.g. multisensory stimulation, deep brain stimulation, and Amantadin, none has gained acceptance or, in case of the positively evaluated Amantadin, bears the risk of epileptic fits. [4]

Non-invasive brain stimulation may be a new therapeutic tool in improving the alertness and awareness in traumatic brain injured subjects with severe disorders of consciousness. In a double-blind shamcontrolled crossover design, Thibuat et al delivered anodal and sham transcranial direct current stimulation (tDCS) in randomized order for 20 minutes over the left dorsolateral prefrontal cortex in acute UWS and MCS patients. [5] The authors concluded that tDCS transiently improved signs of consciousness in MCS patients, a notion supported by the case series of Angelakis et al. [6] By contrast, for chronic patients with severe traumatic brain injury, Lesniak et al., did not find sufficient evidence to support the efficacy of repeated tDCS of the left dorsolateral prefrontal cortex for enhancing rehabilitation of memory and attention as compared to sham stimulation. [7]
Transcranial low-level laser therapy (T-LLT) may be an alterantive to tDCS. Nawashiro et al. had applied 73 bilateral, transcranial near-infrared light-emitting diode (LED) irradiations to the forehead of a single chronic UWS patient. [8] The patient started to move his left hand to reach the tracheotomy tube at the end of the intervention, side effects did not occur. Further, mildly to moderately affected TBI patients, following repetitive self-adminstered T-LLT of the forehead, had reported positive effects on their attention and reaction times.

Accordingly, the authors intended to investigate the potential of frontal T-LLT to imimprove alertness and awareness in traumatic brain injured subjects with severe disorders of consciousness. A baseline treatment design was applied. Five DOC-patients participated, four in the chronic and one in the subacute stage. The Coma Recovery Scale ( $r$-CRS), regarded as the most sensitive scale to detect signs of consciousness, was the primary variable. [9] The hypothesis was a positive effect of T-LTT on arousal and external awareness.

\section{Methods}

\section{Subjects}

Five DOC-patients were studied, tables 1-5 summarize their clinical data including the r-CRS score at trial onset. (Table 1-5) Inclusion criteria were a DOC, hospitalization in either a centre of neurological rehabilitation or a long-term care institution, a brain imaging MRI or CT excluding an acute intra- or extracerebral bleeding, or any condition requiring acute intervention, an EEG excluding a non-convulsive status, and stable medical and pharmacological conditions. Exclusion criteria were metal implants in the brain and pregnancy. A caregiver consented into the individual treatment with the CE-certified laser device. The clinic's ethical committee had approved the study. 
Table 1. Patient \#1.

\begin{tabular}{|c|c|c|c|c|c|c|c|c|}
\hline \multirow{4}{*}{$\begin{array}{l}\text { Diagnosis } \\
\text { Lesion interval at baseline } \\
\text { Measure points (in days) }\end{array}$} & \multicolumn{8}{|c|}{ 57-year old man, severe TBI with multiple frontal contusions, subdural hematoma, spastic dystonic tetrapresis } \\
\hline & \multicolumn{8}{|c|}{29 months } \\
\hline & \multicolumn{3}{|c|}{ Baseline } & \multicolumn{4}{|c|}{ Intervention period } & \multirow{2}{*}{$\begin{array}{l}\text { Follow-up } \\
\text { 70* }\end{array}$} \\
\hline & -21 & -14 & -7 & 0 & 14 & $28 *$ & $42^{*}$ & \\
\hline Brain stem reflex & yes & yes & yes & yes & yes & yes & yes & yes \\
\hline Sleep-wake-cycle & yes & yes & yes & yes & yes & yes & yes & yes \\
\hline Awake-hours per day & 3 & 2 & 3 & 3 & 4 & $5-6$ & $5-6$ & $5-6$ \\
\hline Eye-opening & none & none & none & none & with stimulus & spontaneous & spontaneous & spontaneous \\
\hline Non-verbal interaction & none & none & none & none & Minimal/adequate & Minimal/adequate & Minimal/adequate & Minimal/adequate \\
\hline Best motor response & $\begin{array}{l}\text { pain induced } \\
\text { flexion } \\
\text { withdrawl }\end{array}$ & $\begin{array}{l}\text { pain induced } \\
\text { flexion } \\
\text { withdrawl }\end{array}$ & $\begin{array}{l}\text { pain induced } \\
\text { flexion } \\
\text { withdrawl }\end{array}$ & $\begin{array}{l}\text { pain induced } \\
\text { flexion withdrawl }\end{array}$ & $\begin{array}{l}\text { Voluntary reduced } \\
\text { activity finger } \\
\text { flexors }\end{array}$ & $\begin{array}{l}\text { Voluntary reduced } \\
\text { activity finger } \\
\text { flexors }\end{array}$ & $\begin{array}{l}\text { Voluntary reduced } \\
\text { activity finger } \\
\text { flexors }\end{array}$ & $\begin{array}{l}\text { Voluntary reduced } \\
\text { activity finger } \\
\text { flexors }\end{array}$ \\
\hline Visual pursuit & fluctuating & fluctuating & fluctuating & fluctuating & Visiual pursuit & Visiual pursuit & Visiual pursuit & Visiual pursuit \\
\hline Rankin scale (0-5) & 5 & 5 & 5 & 5 & 5 & 5 & 5 & 5 \\
\hline Barthel Index (0-100) & 0 & 0 & 0 & 0 & 0 & 0 & 0 & 0 \\
\hline $\begin{array}{l}\text { Revised Coma Recovery Scale, } \\
(0-23)\end{array}$ & 3 & 4 & 3 & 3 & 6 & 9 & 11 & 12 \\
\hline Breathing & C-PAP & C-PAP & C-PAP & C-PAP & Passive humidifier & Passive humidifier & Passive humidifier & Passive humidifier \\
\hline Tracheal canula & blocked & blocked & blocked & blocked & un-blocked & none & none & none \\
\hline nutrition & PEG & PEG & PEG & PEG & PEG & PEG/partial orally & PEG/partial orally & PEG/partial orally \\
\hline mobility & Bed-bound & Bed-bound & Bed-bound & Bed-bound & Care wheel-chair & Care wheel-chair & Care wheel-chair & Care wheel-chair \\
\hline
\end{tabular}


Table 2. Patient \#2.

\begin{tabular}{|c|c|c|c|c|c|c|c|c|}
\hline Diagnosis & \multicolumn{8}{|c|}{ 57-year old woman, severe TBI with bifrontal contusions, SAB, akinetic mutism and mild tetraparesis, N. oculomotorius paresis left } \\
\hline Lesion interval at baseline & \multicolumn{8}{|c|}{4.5 months } \\
\hline \multirow{2}{*}{ Measure points (in days) } & \multicolumn{3}{|c|}{ Baseline } & \multicolumn{4}{|c|}{ Intervention period } & Follow-up \\
\hline & -21 & -14 & -7 & 0 & 14 & 28 & 42 & 70 \\
\hline Brain stem reflex & yes & yes & yes & yes & yes & yes & yes & yes \\
\hline Sleep-wake-cycle & yes & yes & yes & yes & yes & yes & yes & yes \\
\hline Awake -hours per day & $3 h$ & $2-3 h$ & $3 h$ & $2-3 h$ & $5 h$ & $7-8 h$ & $8 h$ & $8 h$ \\
\hline Eye-opening & spontaneous & spontaneous & spontaneous & spontaneous & spontaneous & spontaneous & spontaneous & spontaneous \\
\hline Visual pursuit & fixation & fixation & fixation & Visual pursuit & Object-localisation & Object-localisation & Object-recognition & Object-recognition \\
\hline Non-verbal interaction & none & none & none & none & minimal & Reduced/adequate & Reduced/adequate & Reduced/adequate \\
\hline verbal interaction & none & none & none & none & Single words & Short sentences & Short sentences & Short sentences \\
\hline Best motor response & $\begin{array}{l}\text { pain induced } \\
\text { flexion } \\
\text { withdrawl }\end{array}$ & $\begin{array}{l}\text { pain induced } \\
\text { flexion } \\
\text { withdrawl }\end{array}$ & $\begin{array}{c}\text { pain induced } \\
\text { flexion } \\
\text { withdrawl }\end{array}$ & $\begin{array}{c}\text { pain induced } \\
\text { flexion withdrawl }\end{array}$ & $\begin{array}{c}\text { Object } \\
\text { manipulation }\end{array}$ & $\begin{array}{l}\text { Automatic motor } \\
\text { response }\end{array}$ & $\begin{array}{c}\text { Functional object } \\
\text { use }\end{array}$ & $\begin{array}{c}\text { Functional object } \\
\text { use }\end{array}$ \\
\hline Rankin scale (0-5) & 4 & 4 & 4 & 4 & 4 & 3 & 3 & 3 \\
\hline Barthel index (0-100) & 0 & 0 & 0 & 0 & 0 & 0 & 15 & 15 \\
\hline $\begin{array}{l}\text { Revised Coma Recovery Scale, } \\
(0-23)\end{array}$ & 7 & 7 & 8 & 8 & 14 & 18 & 20 & 21 \\
\hline Breathing & spontaneous & spontaneous & spontaneous & spontaneous & spontaneous & spontaneous & spontaneous & spontaneous \\
\hline Tracheal canula & no & no & no & no & no & no & no & no \\
\hline Nutrition & PEG & PEG & PEG & PEG & PEG & Partially oral & Partially oral & Partially oral \\
\hline Mobility & $\begin{array}{l}\text { Care wheel- } \\
\text { chair }\end{array}$ & $\begin{array}{l}\text { Care wheel- } \\
\text { chair }\end{array}$ & $\begin{array}{c}\text { Care wheel- } \\
\text { chair }\end{array}$ & Care wheel-chair & $\begin{array}{l}\text { Functional wheel- } \\
\text { chair }\end{array}$ & stance & $\begin{array}{l}\text { Walking with } \\
\text { rollator }\end{array}$ & $\begin{array}{l}\text { Walking with } \\
\text { rollator }\end{array}$ \\
\hline
\end{tabular}


Table 3. Patient \#3.

\begin{tabular}{|c|c|c|c|c|c|c|c|c|}
\hline Diagnosis & \multicolumn{8}{|c|}{71 year-old man, severe TBI with traumatic SAB, intracerebral bleeding, spastic tetraparesis, N. oculomotorius paresis right } \\
\hline Lesion interval & \multicolumn{8}{|c|}{31 months } \\
\hline \multirow{2}{*}{ Measure points (in days) } & \multicolumn{3}{|c|}{ Baseline } & \multicolumn{4}{|c|}{ Intervention period } & Follow-up \\
\hline & -21 & -14 & -7 & 0 & 14 & 28 & 42 & 70 \\
\hline Brain stem reflex & yes & yes & yes & yes & yes & yes & yes & yes \\
\hline Sleep-wake-cycle & yes & yes & yes & yes & yes & yes & yes & yes \\
\hline Awake -hours per day & $2-3$ & $2-3$ & $2-3$ & $2-3$ & 4 & 4 & $4-5$ & $4-5$ \\
\hline Eye-opening & with stimulus & with stimulus & with stimulus & with stimulus & with stimulus & spontaneous & spontaneous & spontaneous \\
\hline Non-verbal interaction & none & none & none & none & Minimal/adequate & Minimal/adequate & Minimal/adequate & Minimal/adequate \\
\hline Best motor response & $\begin{array}{l}\text { pain induced } \\
\text { flexion } \\
\text { withdrawl }\end{array}$ & $\begin{array}{l}\text { pain induced } \\
\text { flexion } \\
\text { withdrawl }\end{array}$ & $\begin{array}{l}\text { pain induced } \\
\text { flexion } \\
\text { withdrawl }\end{array}$ & $\begin{array}{l}\text { pain induced } \\
\text { flexion withdrawl }\end{array}$ & $\begin{array}{l}\text { pain induced } \\
\text { flexion withdrawl }\end{array}$ & $\begin{array}{l}\text { pain induced } \\
\text { flexion withdrawl }\end{array}$ & $\begin{array}{l}\text { pain induced } \\
\text { flexion withdrawl }\end{array}$ & $\begin{array}{l}\text { pain induced } \\
\text { flexion withdrawl }\end{array}$ \\
\hline Visual pursuit & fluctuating & fixation & fixation & fixation & Visiual pursuit & Visiual pursuit & Visiual pursuit & Visiual pursuit \\
\hline Rankin scale (0-5) & 5 & 5 & 5 & 5 & 5 & 5 & 5 & 5 \\
\hline Barthel Index (0-100) & 0 & 0 & 0 & 0 & 0 & 0 & 0 & 0 \\
\hline $\begin{array}{l}\text { Revised Coma Recovery Scale, } \\
(0-23)\end{array}$ & 8 & 8 & 8 & 8 & 12 & 11 & 12 & 11 \\
\hline Breathing & $\begin{array}{l}\text { Passive } \\
\text { humidifier }\end{array}$ & $\begin{array}{l}\text { Passive } \\
\text { humidifier }\end{array}$ & $\begin{array}{l}\text { Passive } \\
\text { humidifier }\end{array}$ & Passive humidifier & Passive humidifier & Passive humidifier & Passive humidifier & Passive humidifier \\
\hline Tracheal canula & blocked & blocked & blocked & blocked & blocked & blocked & blocked & blocked \\
\hline nutrition & PEG & PEG & PEG & PEG & PEG & PEG & PEG & PEG \\
\hline mobility & $\begin{array}{l}\text { Care wheel } \\
\text { chair }\end{array}$ & $\begin{array}{l}\text { Care wheel- } \\
\text { chair }\end{array}$ & $\begin{array}{l}\text { Care wheel- } \\
\text { chair }\end{array}$ & Care Wheel-chair & Care wheel-chair & Care wheel-chair & Care wheel-chair & Care wheel-chair \\
\hline
\end{tabular}


Table 4. Patient \#4.

\begin{tabular}{|c|c|c|c|c|c|c|c|c|}
\hline Diagnosis & \multicolumn{8}{|c|}{30 year-old woman, severe TBI with multiple brain contusions and SAB, secondary pons infarction, severe spastic tetraparesis } \\
\hline Lesion interval & \multicolumn{8}{|c|}{50 months } \\
\hline \multirow{2}{*}{ Measure points (in days) } & \multicolumn{3}{|c|}{ Baseline } & \multicolumn{4}{|c|}{ Intervention period } & Follow-up \\
\hline & -21 & -14 & -7 & 0 & $14^{*}$ & $28^{*}$ & $42^{*}$ & 70* \\
\hline Brain stem reflex & yes & yes & yes & yes & yes & yes & yes & yes \\
\hline Sleep-wake-cycle & yes & yes & yes & yes & yes & yes & yes & yes \\
\hline Awake -hours per day (h) & $2-3$ & $2-3$ & $2-3$ & $2-3$ & 4 & 4 & $4-5$ & $4-5$ \\
\hline Eye-opening & spontaneous & spontaneous & spontaneous & spontaneous & spontaneous & spontaneous & spontaneous & spontaneous \\
\hline Non-verbal interaction & none & none & none & none & none & Minimal/adequate & Minimal/adequate & Minimal/adequate \\
\hline Best motor response & $\begin{array}{l}\text { pain induced } \\
\text { flexion } \\
\text { withdrawl }\end{array}$ & $\begin{array}{l}\text { pain induced } \\
\text { flexion } \\
\text { withdrawl }\end{array}$ & $\begin{array}{l}\text { pain induced } \\
\text { flexion } \\
\text { withdrawl }\end{array}$ & $\begin{array}{l}\text { pain induced } \\
\text { flexion withdrawl }\end{array}$ & $\begin{array}{l}\text { pain induced } \\
\text { flexion withdrawl }\end{array}$ & $\begin{array}{l}\text { pain induced } \\
\text { flexion withdrawl }\end{array}$ & $\begin{array}{l}\text { pain induced } \\
\text { flexion withdrawl }\end{array}$ & $\begin{array}{l}\text { pain induced } \\
\text { flexion withdrawl }\end{array}$ \\
\hline Visual pursuit & $\begin{array}{l}\text { startle } \\
\text { response }\end{array}$ & $\begin{array}{l}\text { startle } \\
\text { response }\end{array}$ & $\begin{array}{l}\text { startle } \\
\text { response }\end{array}$ & startle response & fluctuating & fixation & visual pursuit & visual pusuit \\
\hline Rankin scale (0-5) & 5 & 5 & 5 & 5 & 5 & 5 & 5 & 5 \\
\hline Barthel index (0-100) & 0 & 0 & 0 & 0 & 0 & 0 & 0 & 0 \\
\hline $\begin{array}{l}\text { Revised Coma Recovery Scale, } \\
(0-23)\end{array}$ & 8 & 8 & 8 & 8 & 10 & 10 & 12 & 12 \\
\hline Breathing & spontaneous & spontaneous & spontaneous & spontaneous & spontaneous & spontaneous & spontaneous & spontaneous \\
\hline Tracheal canula & none & none & none & none & none & none & none & None \\
\hline Nutrition & PEG & PEG & PEG & PEG & PEG & PEG & PEG & PEG \\
\hline Mobility & $\begin{array}{l}\text { Care wheel } \\
\text { chair }\end{array}$ & $\begin{array}{l}\text { Care wheel- } \\
\text { chair }\end{array}$ & $\begin{array}{l}\text { Care wheel- } \\
\text { chair }\end{array}$ & Care Wheel-chair & Care wheel-chair & Care wheel-chair & Care wheel-chair & Care wheel-chair \\
\hline
\end{tabular}


Table 5. Patient \#5.

\begin{tabular}{|c|c|c|c|c|c|c|c|c|}
\hline Diagnosis & \multicolumn{8}{|c|}{$\begin{array}{l}\text { 21-year old woman, severe TBI with traumatic SAB, secondary hydrocephalus, shunt operation with multiple revisions, } \\
\text { ethyl-toxic liver cirrhosis, borderline disease }\end{array}$} \\
\hline Lesion onset & \\
\hline \multirow{2}{*}{ Measure points (in days) } & \multicolumn{3}{|c|}{ Baseline } & \multicolumn{4}{|c|}{ Intervention period } & Follow-up \\
\hline & -21 & -14 & -7 & 0 & 14 & 28 & 42 & 70 \\
\hline Brain stem reflex & yes & yes & yes & yes & yes & yes & yes & yes \\
\hline Sleep-wake-cycle & yes & yes & yes & yes & yes & yes & yes & yes \\
\hline Awake -hours per day & $2-3$ & 3 & 3 & 3 & $4-5$ & $4-5$ & 4 & $4-5$ \\
\hline Eye-opening & spontaneous & spontaneous & spontaneous & spontaneous & spontaneous & spontaneous & spontaneous & spontaneous \\
\hline Non-verbal interaction & none & none & none & none & none & Minimal/adequate & Minimal/adequate & Minimal/adequate \\
\hline Best motor response & $\begin{array}{l}\text { pain induced } \\
\text { flexion } \\
\text { withdrawl }\end{array}$ & $\begin{array}{l}\text { pain induced } \\
\text { flexion } \\
\text { withdrawl }\end{array}$ & $\begin{array}{l}\text { pain induced } \\
\text { flexion } \\
\text { withdrawl }\end{array}$ & $\begin{array}{l}\text { pain induced } \\
\text { flexion withdrawl }\end{array}$ & $\begin{array}{l}\text { pain induced } \\
\text { flexion withdrawl }\end{array}$ & $\begin{array}{l}\text { pain induced } \\
\text { flexion withdrawl }\end{array}$ & $\begin{array}{l}\text { pain induced } \\
\text { flexion withdrawl }\end{array}$ & $\begin{array}{l}\text { pain induced } \\
\text { flexion withdrawl }\end{array}$ \\
\hline Visual pursuit & $\begin{array}{c}\text { Startle } \\
\text { response }\end{array}$ & $\begin{array}{l}\text { Startle } \\
\text { response }\end{array}$ & $\begin{array}{c}\text { Startle } \\
\text { response }\end{array}$ & Startle response & fixation & fixation & Visual pursuit & Visual pursuit \\
\hline Rankin scale (0-5) & 5 & 5 & 5 & 5 & 5 & 5 & 5 & 5 \\
\hline Barthel index (0-100) & 0 & 0 & 0 & 0 & 0 & 0 & 0 & 0 \\
\hline $\begin{array}{l}\text { Revised Coma Recovery Scale, } \\
(0-23)\end{array}$ & 5 & 6 & 6 & 6 & 9 & 9 & 11 & 12 \\
\hline Breathing & spontaneous & spontaneous & spontaneous & spontaneous & spontaneous & spontaneous & spontaneous & Spontaneous \\
\hline Tracheal canula & none & none & none & none & none & none & none & none \\
\hline Nutrition & PEG & PEG & PEG & PEG & PEG & Partially oral & Partially oral & Partially oral \\
\hline Mobility & $\begin{array}{l}\text { Care wheel } \\
\text { chair }\end{array}$ & $\begin{array}{l}\text { Care wheel- } \\
\text { chair }\end{array}$ & $\begin{array}{l}\text { Care wheel- } \\
\text { chair }\end{array}$ & Care Wheel-chair & Care wheel-chair & Care wheel-chair & Care wheel chair & Care wheel chair \\
\hline
\end{tabular}




\section{Design}

A baseline treatment design was chosen, it included a 21-day baseline with four measurement points (D-21, D-14, D-7, and D0), followed by an intervention period of six weeks, daily every workday for 10 minutes, i.e. an overall of 30 treatment sessions. The measurement points were D14, D28, and D42. Follow-up was four weeks after the end of the intervention (D70).

\section{Intervention}

A CE-certified softlaser ("Power Twin 21" by MKW Lasersystem) was used, with a wave length of 785 $\mathrm{nm}, 21$ emitting diodes, $21 \times 50 \mathrm{~mW}$ in the Nogier É mode.The current stimulation frequency of 36,5 $\mathrm{Hz}$ with an impulse length of 0,25 ms emitted 6 J in 10 minutes per emitting diode. The intensity was set to $10 \mathrm{~mW} / \mathrm{cm}^{2}$.

On the level of the superior crest of the fossa sphenoidale five points were marked on the forehead. During each of the 30 sessions, the therapist stimulated each point two times one minute by placing the stimulator onto the skin, i.e. the stimulation was $10 \mathrm{~min}$ in each of the 30 sessions. The patients wore safety glasses. In addition, all patients received ongoing physio-, occupational and speech therapy.

\section{Outcome variables}

Primary variable was the revised version of the Coma Recovery Scale (r-CRS; 0-23). [9]. CRS-R consists of 23 items organized in 6 subscales that address arousal ( $0=$ unarousable $-3=$ attention), auditory ( $0=$ none $-4=$ consistent movement to command), visual $(0=$ none $-5=$ object recognition), motor $(0=$ none/flaccid $-6=$ functional object use), oromotor/ verbal $(0=$ none $-3=$ intelligible verbalization), and communication ( $0=$ none $-2=$ functional:accurate). Scoring is based on the presencce or absence of specific behavioral responses to sensory stimuli administered in a standardized manner. The lowest item on each subscale represent reflexive activity, whereas the highest item represent cognitively mediated behaviors.
The assessment of the r-CRS was recorded and in random order the videos were sent to an experienced external rater, who was unaware of the time points of each video and of the exact purpose of the study. She was on maternity leave and regularly assessed the r-CRS with the help of videos of all DOC patients of the clinic.

Second outcome parameter was the internationally known Barthel Index (BI, 0-100) to asssess the competence in the basic activities of living [10] .

Further, the caregivers answered the following questions at the end of the intervention: how do you rate his/her alertness in the sense of being awake during daytime? how do you rate his/her abilities to communicate (verbal, gestic, mimic) with you? how do you rate his/her emotional response to you? A six-scale ordinal $(-3,-2,-1,0+1,+2$; -3: worse than starting condition; 0 : expectations were met; 2: were considerably exceeded) scale was used.

\section{Statistics}

The non-parametric Pettitt-test was chosen to detect the intraindividual differences over time in comprehension of the several measurepoints. Due to the small number of patients included in this case series, alpha was set to $p=0.10$ to increase the power.

\section{Results}

\section{Patient \# 1}

The 57-year old male subject had suffered a severe TBI 2010. Brain images had revealed multiple intracerebral contusions, a subdural bifrontal hematoma, further the relatives reported that brain anoxia of unknown duration had complicated the clinical course initially. In 2013, he was admitted for ongoing neurological rehabilitation. Clinically he presented an UWS syndrome, a spastic-dystonic tetraparesis, wore a tracheal canula, was intermittently ventilated (CPAP mode) and fed via a percutaneous gastric tube. Brain stem reflexes were intact. Levitiracetam (3000 mg daily) had been prescribed due 
to focal epileptic fits with secondary generalization occurring once a month. During the first four wee$\mathrm{ks}$, the medical situation was stabilized, weaning completed and he was seated in a wheelchair one hour a day. The EEG had shown signs of elevated cerebral excitability, accordingly Vimpat $(2 \times 100 \mathrm{mg}$ daily) was additionally prescribed, the EEG improved. The relatives then agreed to participate in the evaluation.

The initial r-CRS (D-21) score was four, he presented oral reflexes and a strong flexor response to painful stimuli. During baseline, the r-CRS score ranged from 3 to four. The first two weeks of TLLT increased the r-CRS score up to six, he could localize a sound, presented a blinking reflex and the eyes were open. Due to a focal epileptic fit with secondary generalization (it occurred 3 hours after the stimulation, lasted 1 minute approximately, and a lower urinary tract infection had required an antibiotic therapy at the same time), the T-LLT was interrupted for two weeks, and Vimpat medication was increased ( $2 \times 150 \mathrm{mg}$ daily), as the EEG again had showed signs of elevated cortical excitability. During the interruption, the $r$-CRS score dropped to its initial value of three.

Consented by the relatives, the T-LLT intervention was restarted for another four weeks, the $r$ CRS score increased again to a maximum score of 11 at D42. He became able to perform repetitively a visual pursuit with the help of a mirror moved in vertical and horizontal direction in front of his eyes, to protrude his tongue and to move his left hand on demand. Communication via lid closing and opening started but not consistently. The tracheal canula remained and his total dependency on external help did not change. The relatives rated the alertness +1 , communication abilities 0 , and the patients' emotional response +1 . At follow-up, he reached a score of 12 in the $r-C R S$.

\section{Patient \#2}

She was a 57 year old patient admitted for subacute neurological rehabilitation following severe TBI requiring an eight -week acute care and multiple neurosurgical interventions following epidural, traumatic sub-arachnoidal bleeding and multiple brain contusions in the bifrontal region. Due to focal epileptic fits, Levitiracetam (2500 mg daily) had been prescribed in the acute clinic. During the first six weeks of neurological rehabilitation, the patient was weaned, seated in a wheelchair, and the tracheal canula was removed, an EEG recordings had shown no signs of elevated cerebral excitability.

She then presented a severe akinetic mutism in combination with a mild tetraparesis and a left $\mathrm{N}$. oculomotorius paresis, brain stem reflexes were intact, she was totally dependent on external help, fed via a percutaneous gastric tube, and smeared with stool. Amantadin (100 mg daily) successfully improved the patient's condition, but was stopped due to a severe epileptic fit of two minutes duration after 5 days of intake. Lamotrigine $(100 \mathrm{mg}$ daily) was additionally prescribed, the EEG showed no more definite signs of cortical excitability. The caregiver was informed about the pros and cons of another Amantadin or N-LLT therapeutic attempt and opted for brain stimulation.

During baseline, the $r$-CRS ranged from seven to eight, during N-LLT the score improved to 20 (D42), the Follow-up score ( $D$ 70) was 21. At the end of the intervention, she could stand with holding on, walk a few steps assisted by a physical therapist, grasped objects placed in her visual field, ate some food, spoke a few words within the context and became oriented with respect to personal data. Stool smearing had ceased and she helped with basic activities of daily living (the extended Barthel Index had improved from -125 to 15). All activities were executed with marked delay and on external demand only. Side effects had not occurred. The relatives rated the alertness 0 , communication abilities +1 , and the patients' emotional response +1 .

\section{Patients \#3-5}

Three patients were residing in a long-term nursing home. The latencies since brain trauma were at least 
two years. All had suffered a severe traumatic brain injury resulting in an UWS and spastic tetraparesis (patient \#3, \#4 and \#5), for further clinical information see table 3-5. The initial rCRS scores were eight (patients \#3 and \#4), and ranged from five to seven in case of patient \#5.

During intervention, the $\mathrm{r}-\mathrm{CRS}$ score improved in all three subjects, continuously from 8 (D0) to 12 (D42) in both subjects \# 3 and \#4, and from 5 (D0) to 11 (D42) in subject \#5. Subject \# 4 experienced a focal epileptic fit (one 1 min duration) after two days of stimulation, she had no history of epileptic fits, but was on antibiotic therapy after dental surgery. The external neurologist together with the research team decided to halt the stimulation for one week, no antiepileptic medication was given, after stopping the antibiotic therapy the protocol went one. No further epileptic fits occurred. At Follow-up (D70) the positive effects remained stable.

Subject \# 5 started crying during the second half of the intervention when a large mirror was placed in front of her when sitting in a wheelchair.

The relative of subject \# 3 rated the gain in alertness +1 , communication abilities 0 , and emotional response +1 , she further noticed a better postural control of his head while sitting, a notion confirmed by the therapeutic team. The relative of subject \#4 rated the alertness +2 , communication abilities +1 , and the patients' emotional response +1 . For patient \# 5, the corresponding values were $+1,0$, and +1 .

The dependency on external help in ADL activities did not change, the tracheal canula in patient \# 2 could be removed, he started swallowing meshed food, nevertheless feeding via a gastric tube remained.

The statistical analysis over all patients revealed a breakpoint at D28 with a $p$-value of $p=0.069$.

\section{Discussion}

The case studies recommend to further investigate the potential of non-invasive, transcranial N-LLT to promote alertness and awareness in DOC patients following traumatic brain injury. During 30 sessions of 10 min frontal transcranial N-LLT, all patients improved their alertness and external awareness, as confirmed by the rCRS scores and the relatives' impression. One patient in the subacute stage, presenting an akinetic mutism, also improved her mobility and ADL competence.

No statement on the method's effectiveness is warranted, the chosen design did not include a sham therapy, patient \# 2 was in the subacute stage, and no quantitative measurements of awareness were assessed. On the other hand, additional impairments of vision, communication and hearing due to focal brain lesions, limiting the ability to follow the test commands, could not be excluded.

Two patients presented an epileptic fit (focal with secondary generalization, and focal) during the intervention, the events did not occur in direct context with the stimulation, but a causal relationship could not be excluded. In one subject, it was a first time event, the other patient had a known history including an antiepileptic medication, and both patients received an antibiotic therapy at the same time with the stimulation, which additionally lowered the cortical excitability level.

The two chronic UWS patients gained nine and six, the two chronic MCS patients gained six and three points on the rCRS after six weeks of stimulation. Thibaud et al. assessed the effects of a single session of left dorsolateral prefrontal cortex transcranial direct current stimulation (tDCS). [5] Patients with MCS improved for two points and patients with UWS for one point after a single session of tDCS.

Nawashiro et al. had applied 73 bilateral, transcranial near-infrared light-emitting diode (LED) irradiations to the forehead. [8] The patient started to move his left hand to reach the tracheotomy tube at the end of the intervention, side effects did not occur. Mildly affected TBI patients reported that a self-administered repetitive frontal transcranial sti- 
mulation during the night time had consistently increased their attention and reaction times. Concerning healthy subjects, beneficial cognitive and emotional effects had been reported following frontal N-LLT. [11, 12]

Regarding the issue of skull penetration, Jagdeo et al. had reported that near infrared measurably penetrated soft tissue, bone and brain parenchyma in the formalin preserved human cadaveric model. [13] With the transfrontal application one should keep in mind the variable size of the frontal sinus, the bone around the sinus is thicker, and not seldom a sinusitis affects severely affected chronic patients. A thick bone and fluid, however, decrease the speed and thus the power of the near-infrared laser light. [8, 14]

Positive sham-controlled studies in acute stroke patients included the single T-LLT stimulation of 20 points according to the $10-20$ system for one minute each, the wave length was $808 \mathrm{~nm}$ and the intensity $10 \mathrm{~mW} / \mathrm{cm}^{2}$. [15,16,17] In embolized rabbit's brain, Lapchak and De Taboada successfully showed that T-LLT (wave length $808 \mathrm{~nm}$, intensity $10 \mathrm{~mW} / \mathrm{cm}^{2}$ ) significantly increased the cortical ATP, the penetration depth was $20-30 \mathrm{~mm}$. [18] Accordingly the authors of the acute stroke studies speculated that the transcranial laser could have activated the respiratory chain, namely the complex IV, thus increasing the ATP production and helping cell recuperation. $[14,19]$ Regarding the radiation parameters, Drochioiu recommended a wave length of $818 \mathrm{~nm}$ to best activate the NADH pathway of the respiratory chain [19], the device used in the current series emitted a wave length of $785 \mathrm{~nm}$, no other CE-certified laser with a radiation of either 818 or $808 \mathrm{~nm}$ was readily available on the market. With the lower radiation, one may have speculated that the $F A D H 2$ pathway of the respiratory chain had been more activated. However, in the electron transport chain, $\mathrm{NADH}+\mathrm{H}+$ containing $52.52 \mathrm{kcal} /$ mol is used to produce three moles of ATP (17.51 kcal for each mol of ATP), whereas FADH2 with
$35.94 \mathrm{kcal} / \mathrm{mol}$ will produce only two moles of ATP. Local heating and vasodilatation by T-LLT could have been another explanatory effect. [8]

The exclusive frontal application followed the previous clinical reports on the beneficial effects of $\mathrm{N}$ LLT. $[15,20]$ Further N-LLT was assumed to improve the cell metabolism of the stimulated brain areas. In the tDCS trials, the authors stimulated the left dorsolateral prefrontal cortex (DLPF) which is said to receive visual and and somatosensory input from the parietal heteromodal association cortices regarding vision, motion, spatial orientation and tactile sensations, and projects to subcortical monoaminergic and cholinergic sources. [5] . The current protocol also included the stimulation of the right DLPF, which has been linked to maintenance of sustained arousal and attention, which is similarily relevant for patients with DOC. Further safety issues in N-LLT protocols so far recommended to stimulate several points for shorter periods of time (1-2 minutes per site) and not stationary over a longer period of time, as in tDCS.

Limitations of the study were the absence of a control group, the absence of MRI-based mapping of the stimulated area, given the presence of focal damage and atrophy, and no quantitative assessment of attention and awareness. Profound clinical implications are thus not warranted, future clinical trials could concentrate on patients with an akinetic mutism after TBI. Ethically, team members raised the issue whether the promotion of awareness was beneficial to the patients; subject \#5, for instance, started crying when seeing herself in a large mirror during the second half of the intervention period.

\section{Conclusions}

In summary, 30 sessions of 10 min of frontal T-LLT increased the alertness and awareness in five traumatic brain injured subjects with severe disorders of consciousness. Epileptic fits were potential side 
effects. No statements on the effects of the noninvasive intervention are warranted, future studies including sham therapy and quantitative assessment of awareness are needed.

\section{Acknowledgment}

The "Verein zur Förderung der Hirnforschung \& Rehabilitation e.V." supported the case series

\section{References}

1. Ahmadi SA, Meier U, Lemcke J.Detailed long-term outcome analysis after decompressive craniectomy for severe traumatic brain injury. Brain Inj 2010; 24: 1539-49.

2. Laureys S, Faymonville ME, Berre J. Rapid response: Permanent vegetative state and persistant vegetative state are not interchangeable terms. BMJ 2000; 321: 916-21.

3. Dolce G, Lucca LF, Candelieri A, et al. Visual pursuit in the severe disorder of consciousness. J Neurotrauma 2011; 28: 1149-54.

4. Giacino JT, Whyte J, Bagiella E et al. Placebo-controlled trial of amantadine for severe traumatic brain injury. N Engl J Med 2012; 366: 819-26.

5. Thibaut $A$, Bruno MA, Ledoux $D$, et al. tDCS in patients with disorders of consciousness: a sham-controlled randomized double-blind study. Neurology 2014; 82: 1112-18.

6. Angelakis E, Liouta E, Andreadis $\mathrm{N}$ et al. Transcranial direct current stimulation effects in disorders of consciousness. Arch Phys Med Rehabil 2014; 95: 283-9.

7. Lesniak M, Polanowska K, Seniow J et al. Effects of repeated anodal tDCS coupled with cognitive training for patients with severe traumatic brain injury: a pilot randomized controlled trial. J Head Trauma Rehabil 2014; 29: 20-9.

8. Nawashiro H, Wada $K$, Nakai $K$, et al. Focal increase in cerbral blood flow after treatment with near-infrared light to the forehead in a patient in a persistant vegetative state. Photomed Laser Surg 2012; 30: 231-33.

9. Giacino JT, Kalmar K, Whyte J.The JFK coma recovery scale revised: measurement characteristics and diagnostic utility. Arch Phys Med Rehabil 2004; 85: 2020-29.

10. Mahoney FI, Barthel DW. Functional evaluation: The Barthel Index. MD State Med J 1965; 14: 61-65.

11. Charland-Verville V, Habbal D, Laureys S, et al. Coma and related disorders. Swiss Arch Neurol \& Psych 2012; 163: 265-72

12. Konstantinovic LM, Jelic MB, Jeremic $A$, et al. Transcranial application of near-infrared low-level laser can modulate cortical excitability. Lasers Surg Med 2013; 45: 648-53.

13. Jagdeo JR, Adams LE, Brody NI, et al. Transcranial red and near infrared light transmission in a cadaveric model. Plos One 2012; 7: e47460
14. Karu T. Mitochondrial mechanisms of photobiomodulation in context of new data about multiple roles of ATP. Photomed Laser Surg 2010; 28: 159-60.

15. Zivin JA, Albers GW, Bornstein N. Effectiveness and safety of transcranial laser therapy for acute ischemic stroke. Stroke 2009; 40: 1359-64.

16. Lampl Y, Zivin JA, Fisher M. Infared laser therapy for ischemic stroke: a new treatment strategy: results of the NeuroThera effectiveness and safety trial-1 (NEST-1). Stroke 2007; 38: 184349.

17. Schellinger PD, Köhrmannn M. Nah-Infrarot-Lasertherapie beim akuten Schlaganfall. Nervenarzt 2012; 83: 966-74.

18. Lapchak PA, DeTaboada L. Transcranial near infrared laser treatment (NILT) increases cortical adenosine-5-triphosphate (ATP) content following embolic stroke in rabbits. Brain Res 2010; 1306: 100-05.

19. Drochioiu G. Laser-induced ATP-formation: mechanism and consequences. Photomed Laser Surg 2010; 28: 573-74.

20. Hashmi JT, Huang YY, Osmani BZ. Role of low-level laser therapy in neurorehabilitation. PMR 2010; 2: 292-305.

\section{Comment on this article:}

\section{(f) $[3$ in $8+\mathbf{S} P$}

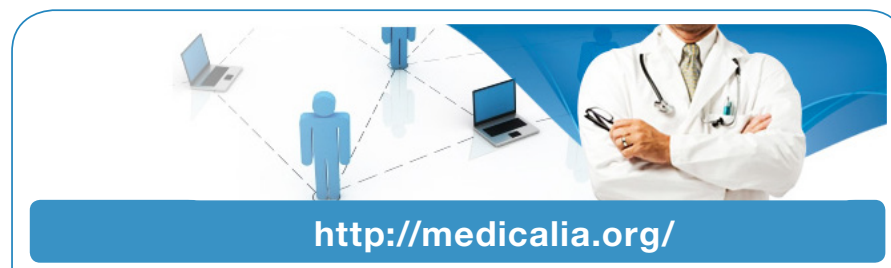

Where Doctors exchange clinical experiences, review their cases and share clinical knowledge. You can also access lots of medical publications for free. Join Now!

\section{Publish with iMedPub}

http://www.imed.pub

International Archives of Medicine is an open access journal publishing articles encompassing all aspects of medical science and clinical practice. IAM is considered a megajournal with independent sections on all areas of medicine. IAM is a really international journal with authors and board members from all around the world. The journal is widely indexed and classified Q1 in category Medicine. 